\title{
Atmosphere in radio and architecture: Using The Revenge radio play in interdisciplinary teaching as a means to understand notions of abstraction and the tensions between materiality and immateriality in building physical and imagined spaces
}

Evi Karathanasopoulou, Bournemouth University

\section{Abstract}

This article reflects upon an innovative international teaching collaboration between scholars and students in radio studies and architecture. In particular it presents an analysis of some of my work with a group of first-year architecture students in a workshop co-designed with two of their architecture lecturers, Dimitra Pavlakou and Athanasios Zagorisios. The focus of the workshop was Andrew Sach's binaural radio play The Revenge (1978). The aim was to investigate the relationship between perception and representation and to help students understand notions of scale, materiality, structure and form. The questions raised by the workshop concerned the degree of abstraction that penetrates the above relationships. This article offers an analysis of some of the student work that derived from that workshop. It looks at how our understanding of the core architectural concepts of materiality and immateriality might be subverted when considered through radio theory and practice. The idea of Atmosphere is used as a core concept crucial to both radio and architecture.

Atmosphere is considered as an immaterial, abstract notion deriving from the material hypostasis of a building or a highly constructed audio story-world. Abstraction is considered as a notion that allows for atmosphere to be created in radio and architecture. Atmosphere and abstraction finally emerge as interdisciplinary concepts, 
connecting architecture and radio through the idea of space; the latter seen as a construct both material and immaterial, defined and yet in many ways free.

\section{Keywords}

radio

architecture

abstraction

materiality

atmosphere

intimacy

education

\section{Introduction}

This article looks at how a binaural radio play was used in an interdisciplinary workshop for a cohort of first-year architecture students. It demonstrates how Andrew Sachs' The Revenge (BBC 1978), was framed through some of the basic principles of teaching audio media combined with some of the main principles of teaching architecture. Namely, examining the emotive capacity of the non-visual elements of physical and imagined worlds. The discussion here considers the extent to which this classroom task helped the students negotiate and understand the tensions between materiality and immateriality in architecture by looking at how these two concepts might inform the building of physical and imagined spaces. Furthermore, this article offers a critical reflection upon current understandings of imagined space in radio studies. The latter is achieved by using the conceptual lens of atmosphere in architecture in order to examine the construction of atmosphere in radio drama. 
The workshop was designed by myself, an audio media theorist, practitioner and educator at Bournemouth University in the United Kingdom, along with two architecture lecturers at the Department of Architecture of the University of Patras in Greece, Dimitra Pavlakou and Athanasios Zagorisios. They invited me to design a sound-based session as part of their lecture series Dialogical Architectures: Landscape, Objectscape, Soundscape. In the workshop, the students were asked to listen to The Revenge, an experimental radio play 'without words' recorded in 'binaural stereo', on location (BBC, 1978). They were asked to create architectural drawings depicting the story and the story-world of The Revenge based on their interpretation of it. In this lecture series, Pavlakou and Zagorisios wanted the students to grasp the notion of architecture as existing and happening beyond the built environment. Upon listening to the radio drama, students were asked to consider radiophonic space and propose their interpretations of it. The students had the freedom to use common architectural concepts such as width and height but also intangible notions such as object-space interactions and emotional space.

\section{Theoretical Context}

By combining radio theory and architectural theory, this article offers an analysis of some of the student work that derived from that workshop, from my point of view as a radio theorist. It looks at how using this radio play seems to have subverted and challenged some of the ways in which the core architectural concepts of immateriality and materiality are taught and understood at this early stage in an architecture degree. The analysis builds on the idea of atmosphere as a core concept crucial to both radio and architecture. Atmosphere is the the connecting joint between the two disciplines. 
It is used here as the bridge between materiality and immateriality because it is considered as an immaterial, abstract notion, which derives from the material hypostasis of a building. The idea of abstraction will eventually be considered as a notion that allows for 'atmosphere' to emerge.

In an article for the Journal of Architecture, Sabine von Fischer and Olga Touloumi, highlight that '[d]espite its ubiquity, sound is largely missing from histories of architecture and the built environment' (2018: 873). And yet, in academia today there is a sense of a strong connection between sound and architecture with some important works that sketch some of the ways that the two intersect. Their focus varies from acoustics and music to radiophony; the latter being of particular interest here. The themes explored by scholars range from the internal architecture of radio studios (Yusaf 2012), to architect Mark Wigley's Buckminster Fuller Inc: Architecture in the Age of Radio that looks at radio as the fundamental site of architecture today (2015). However, one struggles to find much work that specifically looks at the connections between radio drama and architecture.

In Geographies of Urban Sound, Torsten Wissmann uses two radio plays as case studies in order ask questions about the ways in which place is represented in the media (2014: 203). He asserts that, "[i]n the case of audio drama and the creation of the city through sound, language seems to be insufficient for fully communicating place' (2014: 203). My work here aims to build onto this idea by exploring how the analysis of an audio drama consisting solely of non-verbal sounds may offer some answers. 
One of the main texts used here is architect Peter Zumthor's book Atmospheres (2006). Zumthor's definitions of atmosphere will assist in providing an analysis of The Revenge radio play and the students' response to it. Architect Juhani Pallasmaa's book The Eyes of the Skin: Architecture and the Senses (2012) will be used as another connecting link between architecture and radio theory. The article will consider the seemingly antithetical ideas of abstraction and structural precision and their significance not only in architecture but, importantly, in the creation and study of audio media today - particularly as binaural and immersive audio technologies are taking centre stage in the current media landscape. In this article I argue that atmosphere should be understood as an interdisciplinary concept, connecting architecture and radio through the idea of space; the later seen as a construct both material and immaterial, defined and yet in many ways free.

In the next section I will further outline core concepts and definitions, to provide theoretical and conceptual connections between architecture, radio and The Revenge radio play in particular.

\section{Binaural audio}

Binaural audio is an immersive audio technology that aims to make the listener feel like they are within a space, as that appears in an audio recording. The audio is recorded with special microphones that aim to imitate the experience of listening while being in a real environment. Listening to this recording needs to happen either through headphones, which is the most common, or through a special set up of loudspeakers. The Revenge radio play was produced for headphone listening. Roginska and Geluso provide a short description of what the effect is: 
Binaural Audio reproduction techniques take advantage of the human natural spatial auditory cues to recreate a virtual auditory environment through headphones or loudspeakers that emulate headphone reproduction. This results in a 'you are there' first-person perspective. (2017: vi)

The 'you are here' perspective places space in the centre of what binaural audio storytelling does and can do (through the recording of actuality and sound effects). Sachs' 1978 work takes this idea a step further by completely removing words, the only other main audio story-telling tool. The listener now is not only placed in a 'you are here' scenario but in a 'you are' scenario, as they experience the story from the point of view of the protagonist. As we become the body of the protagonist but not his brain, we do not know what he thinks but we know what he does. The drama and tension in this thriller is created through this character's interaction with spaces and objects. In what we might call a tactile audio story, space and place are in a way the other 'characters' in this play. Space - created, through actuality, is the story. Recorded on location, The Revenge aims to emulate the real atmosphere of the spaces the protagonist inhabits.

\section{Atmosphere: From Crook to Zumthor to Sachs}

In media studies, atmosphere is a technical term referring to the sounds around a story: those sounds that evoke a space/place/situation. Tim Crook outlines a 'critical matrix for an academic textual analysis of sound (2012: 16). In that matrix he defines 'soundscape/atmosphere and sound effects': 
This is the sound environment or sound frame for any mise-en-scène. It punctuates the identification of location, context, world, time and can also constitute characterisation and support characterisation. An atmospheric track belonging to the world of the story that is known to and immerses the participants of a narrative, but sometimes it can exist in a parallel world only known to the audience. Sound effects support and deploy in the events and action of a plot. (2012: 16)

Atmosphere may be created by recording the sound of a physical space/location and by recreating a space or situation with the use of sound effects. In audio production these sounds will also evoke imagined spaces within a listener's head (particularly in drama). Sachs, who wrote and performed The Revenge, created a story told through actuality; thus, we might deduce that atmosphere is the main story-telling tool here, particularly as the voiceless protagonist moves through space and inhabits a range of different places. These places offer - instead of words - a tactile sonic geography for the listener to 'read' with the ear and, by doing that, allowing her to make sense of what is happening in the story. Crook's definition is pertinent as it recognizes the importance of atmosphere not merely as signposting location but assisting characterization. In The Revenge atmosphere is crucial: as the main storytelling tool it describes the spaces that the protagonist inhabits but also constitutes characterization by becoming the protagonist (Crook 2012: 16).

In architecture, atmosphere is a slightly more elusive concept and yet one that architect Peter Zumthor considers central to the character of a space. Zumthor describes atmosphere as the 'Magic of the Real' (2006: 19). He writes, 'I enter a 
building, see a room, and - in the fraction of a second - have this feeling about it' (2006: 13). Architecture educator James Burch, referring to Zumthor's approach, notes that: '[a] predominant strand of contemporary criticism identifies the creation of atmosphere as the way in which an architectural space is distinguished from the 3dimensions of physical buildings' (2015: 2). Zumthor avoids simply describing a building through its main structural components (e.g., walls, windows, ceilings), opting for an immaterial reading of a space that takes into account multiple sensory details, spatial context and the relationships of the building with its surrounding world. ${ }^{1}$

If we compare this notion to Sach's decision to tell an audio story without dialogue, we might say that he also opted out of the main structural material of a traditional audio story: words. Creating, thus, a perhaps ambiguous, yet highly and precisely constructed artefact.

There have been various, often valid, criticisms that the story in The Revenge is ambiguous, because there are no words in it. Shingler and Wieringa assert that, 'whilst the sound effects and acoustics can successfully convey something of the what, the where and the how, they are incapable of dealing with the why' (1998: 53, my emphasis added]. The sound world of The Revenge is, indeed, 'abstract'. Like all radio, it is made with the aim to be completed through the individual listener's imagination (in this of course lies much of radio's power). In this case, the level of abstraction is higher because of the absence of voice. Yet, the sound-world in the story is highly constructed. Rudolf Arnheim, very early on in radio theory, encapsulates this paradox while writing about radio drama: 
[...] radio drama, in spite of the undeniable features of an abstract and unearthly character, is capable of creating an entire world complete in itself out of the sensory materials at its disposal - a world of its own which does not seem defective or to need the supplement of something external such as the visual. (1936: 137-38)

Andrew Sachs when talking about creating the play was not only concerned with abstraction; that is, creating a story without words. But, equally, he was looking for specificity. In a radio interview to Peter Reed, discussing how the idea for the play came to him, Sachs describes how he strived for specificity:

I thought, now what sound cannot be misinterpreted to a listener who can't see anything? And I thought well what about a fridge door? With a milk bottle inside. And somebody shuts [the door]. And the sound of the door shutting plus the slight rattle of the milk bottle, can't be anything else. (I Did It my Way: Andrew Sachs 2017)

Sachs seems to have been trying to create an immersive story by using realism while retaining radio's positive ambiguity. The sonic manifestation of the materiality of objects and spaces, like a house, a busy street, a river, a prison, are Sach's replacement for words. And whilst they are material in essence, their emotive power in this play lies in the fact that they eventually create a story based on abstraction. Juhani Pallasmaa, referencing the work of Walter J. Ong, asserts that hearing puts the human at the centre of the cosmos, and by doing that it 'structures and articulates the 
experience and understanding of space' (2012: 53). Hence, a response to Shingler and Wieringa's question about the 'why' in the story of The Revenge might be that the 'why' is insignificant. Instead, the play seems to be an exercise in placing the 'what, how and where' at the centre. Thus, going back to a more primal experience of the world, with the listener placed in the moment when the action is taking place, experiencing the story from within rather than from outside. The listener here, through binaural technology, experiences the story as an embodied experience, rather than as the afterthought of an observer. Walter J. Ong writes that, 'though words are grounded in oral speech, writing tyrannically locks them into a visual field forever $[\ldots]$ a literate person cannot fully recover a sense of what the word is to purely oral people' (quoted in Pallasmaa 2012: 28). Sachs, in his quest to make a play without words, made up of sounds that - in his view - cannot be misinterpreted, seems to be going back to a fundamental experience that is defined by those things that are tactile yet not always tangible - an atmosphere that is emotive yet not prescribed; an atmosphere that derives from a carefully designed and built structure; an atmosphere which is part of the structure that it evokes and yet it is elusive, subjective and immaterial.

Let us go back to Zumthor's 'magic of the real' as a definition for atmosphere in architecture; and let us consider how to him, a space is not just defined by those material components that one can easily see and touch, but through the immaterial, hard to define, emotive states it can evoke to an inhabitant (2006: 19). Radio is also defined by an often hard to grasp intimacy, partly deriving from its immateriality. ${ }^{2}$ In the case of The Revenge, a close connection is created between the listener and the protagonist not through the voice, as one might have expected, but through the 
intimation of space - precisely, yet ambiguously. Juhani Pallasmaa enforces this notion of intimacy through a sense of space that is not, however, tied to vision:

Sight isolates, whereas sound incorporates; vision is directional, whereas sound is omni-directional. The sense of sight implies exteriority, but sounds creates an experience of interiority. I regard an object, but sound approaches me; the eye reaches, but the ear receives. Buildings do not react to our gaze, but they do return our sound back to our ears. (2012: 53).

This paradox of highly constructed spaces (physical or otherwise) with strong emotive, immaterial qualities is true for both radio and architecture. It is important to note here that while this article in some occasions uses the terms abstraction and immateriality interchangeably, they both aim to evoke an antithesis to materiality. In each occasion one of the two is used based on the intricacies of the surrounding analysis. Without reducing the two to the same meaning, the article works on the premise that there might be some overlap between these terms.

\section{Methodology: Educational context}

When asked to produce a task for these first-year architecture students in which they would consider the tensions between materiality and immateriality, I decided to use The Revenge and the idea of atmosphere in order to link the two disciplines (audio production and architecture).

It is important here to note that considering the tensions between materiality and immateriality in the teaching of architecture is one of the first things young architects 
have to grapple with. The use of the concept of atmosphere is also not unique to this project. James Burch highlights the importance of atmosphere in helping architecture students navigate the tensions between the material and the immaterial in architecture.

$[\ldots]$ the theory that there is an experiential and associative aspect to the creation of architectural meaning is a foundational aspect of architectural teaching; and most first year courses in architecture include design exercises that require students to respond creatively to some form of charged atmospheric stimulus. The challenge presented to students in this type of project is how they might connect concepts and abstractions to artefacts they might be studying or making. (2015: $3-$ 4)

As Burch notes, there are two routes that teachers usually take: they go either from abstraction into materiality or the other way around (2015:3-4). In the first case, the students are given one or a few words/ ideas as abstractions from which to create architectural drawings. In the second case, through the observation of real environments and the recording of these environments by means such us drawing and photography, the students will derive more abstract artefacts such as other drawings and maquettes. It is important here to note that the article regards Burch's use of the term abstraction to be closely related to both the ideas of atmosphere and immateriality.

The workshop, designed in collaboration with the two architecture lecturers from the University of Patras, was different in that our approach did not ask the students to use either one of these two routes. Prior to listening and drawing, there was no attempt to 
pre-define any such notions of what radio is and does or how the story in The Revenge is constructed. We neither defined the story-world in the radio play as material or immaterial, nor attempt to define radio space in general as material or immaterial. Rather, the students were simply asked to create drawings based on what they heard.

The goal was to explore whether radio can be used in the teaching of architecture as a metaphor for the strong, often unexpected and tense connections between materiality and immateriality. The aim was also to determine whether the students' work would confirm my suspicion that radio space can allow for a different kind of creative thinking; one which would derive from a further blurring of the boundaries between immateriality and materiality - eventually arriving at an alternative understanding of the concept of abstraction.

Although the premise of this workshop is not unique, radio drama is not typically used in education as a trailhead for the creation of architectural designs. Ted Sheridan and Karen Van Lengen detail an architectural studio/workshop that they ran in 2000 at the University of Virginia School of Architecture that aimed to bring the study and use of sound to the forefront of architectural practice and education. Here students used aural memories in order to create architectural drawings. Sheridan and Van Lengen note, 'Sometimes their memories resulted in abstract or interpretive representations, whereas others documented the actual place of the sound by delineating its architectural features' (2003: 42). This is a type of subversion that we also noted in the student work depicting the aural world of The Revenge. 
Architect and architectural theorist Marco Frascari, wrote about the significance of architectural drawings and the 'synesthetic' process that architects like Carlo Scarpa used in their work,

Since their beginning, architectural drawings have evolved within specific manifestations of non-verbal thinking and tacit knowledge, realized by either involuntary or purposeful comparison of the impressions of different modalities, drawing from structural or semantic and, most of all, emotional similarity. Drawings become aural-aromatic-chromatic-visual substitute for flavoring buildings. The mixing of factual lines and non-factual demonstrations is that architects, in their tracings are not making transparent notations but synthetic images. (2011: 143)

In this task, we saw radiophonic space and active radio listening as an apt exercise in this type of synthetic process. Here we aimed to tease out what Shudana Yusaf has termed the 'oxymoronic relationship between the placelessness of radiophony and the situatedness of architecture' (2014: xvi). But even more pertinently, we also set out to challenge our understanding of what abstraction means when it comes to radio space. The Revenge, due to its use of space as a main story-telling tool, was particularly fitting for this task

Interestingly, some of the students seem to have moved from 'materiality' to 'immateriality' and others, from 'immateriality' to 'materiality'; while others may have done a combination both. I place these words in inverted commas here because our pre-conceived notions of them seem to be challenged through the student 
drawings, in the context of both radio and architecture. In the act of interpreting the story-world of this radio play, and without any preconceptions, the students provided us with some evidence that radio space can subvert and partly question traditional perceptions of abstraction.

The Oxford Dictionary defines abstraction as the 'process of stripping an idea of its concrete accompaniments' (1951: 6). Here, through this exercise, each student seemed to define these 'concrete accompaniments' very differently. That is, for some the sound was the concrete essence of the space/story and they, thus, had to reduce it to more abstract designs. For others, the sound was the abstraction of a more concrete space/story-world that they then defined through their drawings. Some students used symbolism, others depicted rhythm, some even noted materials and elevation levels; each choosing to work to a different degree of abstraction. I argue that the students were evoking, in the form of drawing, what the radio listener does in her head: being a co-creator of the imagined worlds presented to her ears, adding as much or as little as she wants in order to complete an abstract yet highly constructed picture.

\section{Four Drawings}

In this section, four student drawings will be analysed as case studies in order to further explore a subversion in the tension between materiality and immateriality and to question what abstraction might mean when building sonic spaces and storyworlds. This is a subjective analysis, yet grounded within the ideas and principles explored in the first part of this article, acknowledging that psychoanalytical or architectural analyses might have offered different insights. This is my response as a media educator upon receiving these drawings and it is separate from the discussion 
that happened in the classroom between the architecture lecturers and the students. For the purposes of this article, of approximately 95 drawings, I choose four that were representative of the student work in the workshop. The exercise was formative and the work was not marked, but it was given verbal feedback. The work was categorized by myself, Pavlakou and Zagorisios based on levels of abstraction and/or symbolism used. The four drawings selected here depict the extremities of these categories as well as a middle ground.

1.

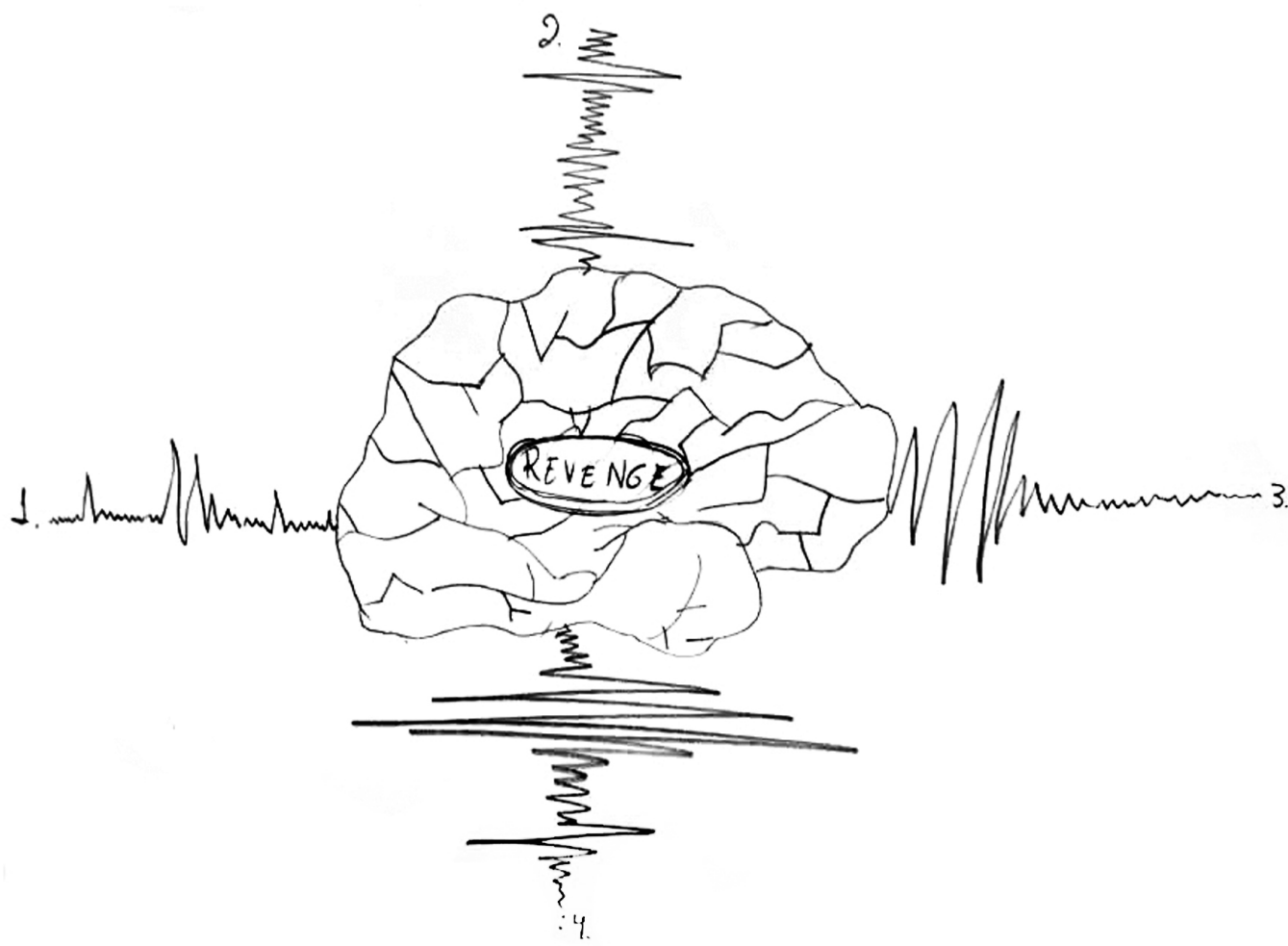

Figure 1. Drawing by Margarita Koulouri

The first drawing, Figure 1, is an abstract depiction of what happens in the story, yet the way it holds the only word the listener is given - revenge - into place, is striking. In terms of audio production, the 'atmosphere' in The Revenge is the only carrier and driver of the story. It seems to be depicted here as a sonic construction that stands 
firmly around the main protagonist and holds him into place and into the centre of the story - like a web of sonic beams. Perhaps, this design offers a candidate for an answer to the 'why' of the story. The word stands in the place of the person through whose body and point of view the listener experiences the story.

The student has circled the one 'material', tangible element given to them, the word 'revenge', and has placed it within two imagined abstract constructions: the first, resembling a brain, the locale where much of radio stories are in fact created; and the second, depicted in four abstract - yet evocative of rhythm - lines, that for this student seem to define the story. Going back to Pallasmaa and his consideration of Ong's work on Orality and Literacy, we see here a tension between the written word and the aural. Pallasmaa sees architecture as artistic practice with similarities to poetry, noting that '[a]rtistic expression is engaged with pre-verbal meanings of the world, meanings incorporated and lived rather than simply intellectually understood' (2012: 28). Pallasmaa uncovers here a tension between language and lived experience, where ' $[\ldots]$ the task of art and architecture in general is to reconstruct the experience of an undifferentiated interior world in which we are not mere spectators, but to which we inseparably belong' (2012: 28). In this early example of binaural radio experimentation, Sachs intends to do just that: immerse the listener into a nonverbal story-world, which she can experience from within. Sachs, arguably ahead of his time, superimposes the listener onto the protagonist, while the creation and experience of space is the main event. The student's work in Figure 1 seems like a blueprint for what binaural audio does. At a time when headphone listening is becoming the dominant listening practice and binaural recording is a re-emerging technology, there is great value in considering this idea of superimposition. 


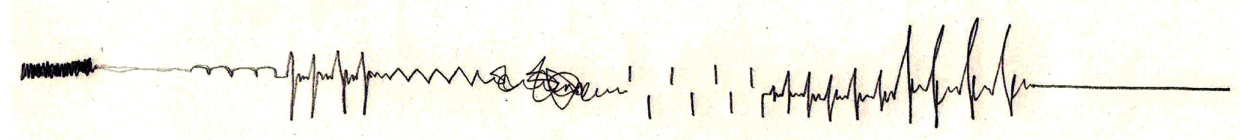

Figure 2. Drawing by Panagiota Papadopoulou

One of the nine elements that compose the 'magic of the real' in architect Peter Zumthor's book Atmospheres is called 'Between Composure and Seduction', meaning 'the way that architecture involves movement' (2006: 41). Zumthor further defines this notion by adding the element of time: 'Architecture is a spatial art [...] But it is also a temporal art (2006: 41).

Radio might also be defined as a spatial art for its ability to construct worlds within the mind of its listener and its ability to superimpose imagined worlds onto lived surroundings. David Hendy argues that 'creating a sense of place is one recurring theme of radio's meaningfulness in modern life' (2000: 177, original emphasis). He further explains this notion by talking about radio's ability to transform 'our sense of space between different places' (2000: 177, original emphasis). This is pertinent to our discussion as binaural audio aims to achieve listener immersion to an extreme.

Radio might also be called a temporal art not only for its structural dependence on rhythm and the way that it connects to the everyday lives of its listeners but also for its ability, due to the lack of vision, to bring temporality to the forefront of the listening experience. Through imagination, the radio text allows for spatial as well as 
temporal superimposition. Kate Lacey, writing about imagination and the idea of 'travelling' through listening to the radio, notes that,

the gap between "imaginative visiting"" and "engaged listening"" may be productively narrowed by recognizing that listening, particularly in relation to storytelling and other forms of mediated encounter, involves the imagination in travelling across boundaries physical, personal, social and temporal. (2013: 191)

Indeed, the student that created the drawing in Figure 2 seems to be experiencing the story in time, as well as in space. The rhythmical patterns here can be read as a radiophonic score, inclusive of pauses for silence. As mentioned earlier, the story is designed sonically in order to make the listener feel like they are experiencing events from the point of view of the protagonist. The absence of the voice of a protagonist or narrator takes away a sense of hindsight, afterthought or listening to this story retrospectively. By removing as many layers of separation as possible between the listener and the protagonist, by superimposing one over the other, the story seems to be placing the listener not only within the space of the story but also within the time of the story. The listener here inhabits the locale of the story-world in full synchronicity with the protagonist.

The question of abstraction here becomes a complicated one. The student has recovered the temporal element of the story and has translated it in a design that looks like a waveform, a timeline, a rhythmical representation of different events in the story. These events are represented through abstract lines, sometimes straight, 
sometimes a tangled mess, other times in a staccato of pauses and small parallel lines. As time itself is an elusive concept, it is difficult to assert if the temporal element was perceived as an abstract notion and turned into a more defined design, or if the design is an abstract representation of the temporal lived experience of the listener. However, what is clear is that the listening experience was depicted as an experience of time.

3.
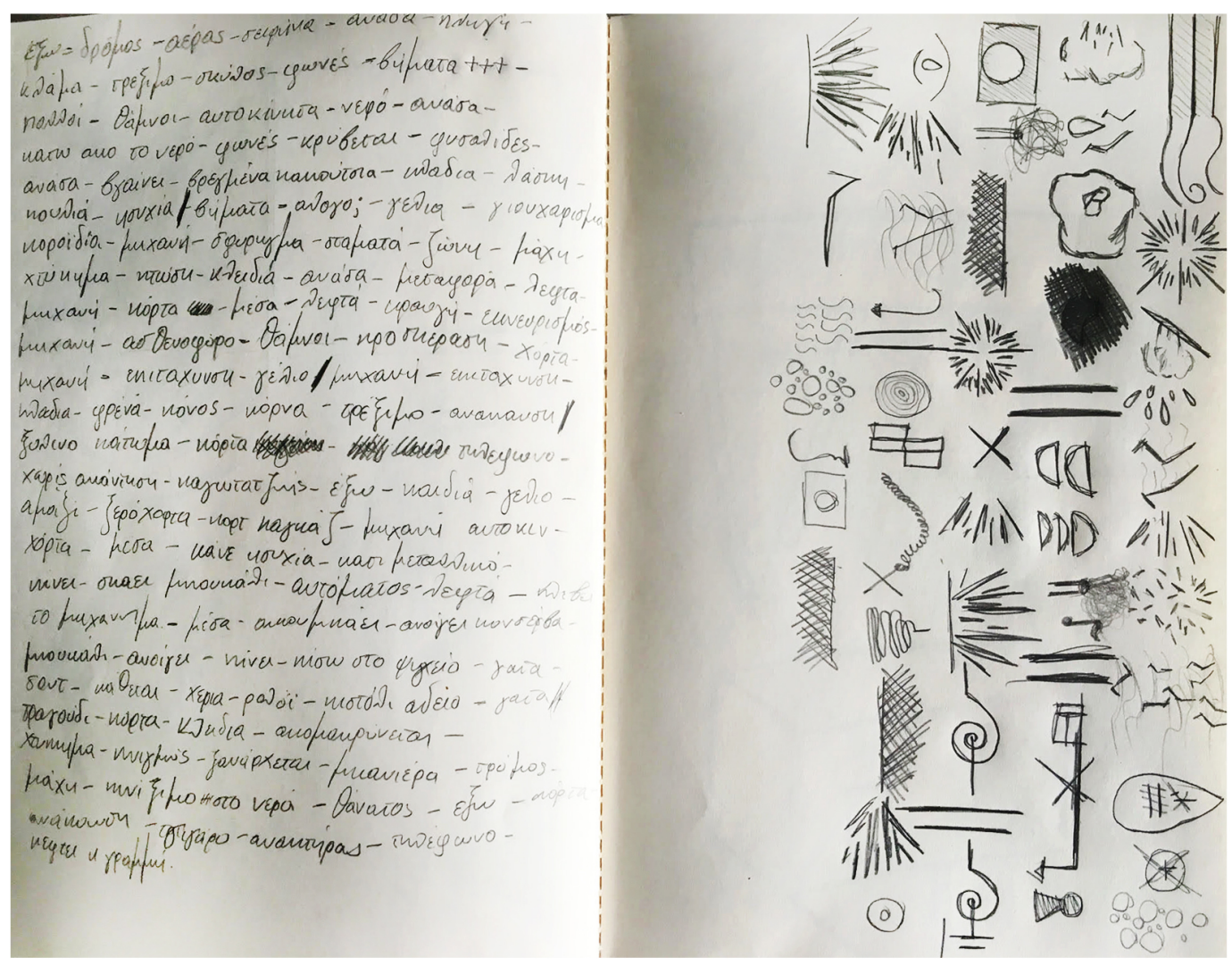

Figure 3. Drawing by Panagiotis Theodorakopoulos

Another of the nine elements of Zumthor's 'magic of the real' is described as

'Materials \& Surrounding Objects', meaning 'the things that people keep around them' (2006: 37). What the student design in Figure 3 does is rather interesting. On the right-hand side of their notebook, the student has created symbols for those things that they can hear in the story: water, feet walking, a keyhole and so on. Some of 
these are representational and easy to assign to an object, situation or action, while others are abstract. On the left-hand side, they have noted (in Greek) everything that they can hear in words; this includes: objects, actions, conditions, living beings. As an example, some of these are: outside, street, hiding, bubbles, dog, acceleration, death, telephone. There are a few layers to unpack here. The student has clearly noted materials and surrounding objects, and they have done that in a way that positions these sonic representations as both specific and abstract. On the left, they have taken the sounds that Sachs considered as non-negotiable in terms of meaning, and turned them into the thing that Sachs decided to omit: language. Not only that, but a play without words made by a British artist is fluently translated here into the Greek language. This is a radio play that transcends language, yet in this drawing, language becomes one of the ways in which the story is 'materialized' onto the page.

On the one hand, if we consider radio space as one of relative abstraction, then language is the thing that grounds that space into specificity. On the other hand, the student deconstructs these words into symbols of varying levels of abstraction. There are several tensions here between the aural, oral and visual. Pallasmaa, when considering our transition from oral to written culture, quotes Ong who in turn considers written language and its connection to vision: 'the shift from oral to written speech was essentially a shift from sound to visual space' (Ong quoted in Pallasmaa 2012: 27). Pallasmaa further refers to Ong's idea of this shift by bringing abstraction into the discussion: 'as hearing-dominance has yielded to sight-dominance, situational thinking has been replaced by abstract thinking' (2012: 27). Here words are considered visual yet abstract and sound is considered situational and closer to the lived experience of a space. This is an interesting subversion because radio sound 
tends to be considered as rather subjective (this is due to the role the listener's imagination plays in the construction of meaning). And yet, it makes sense, because radiophonic intimacy is connected to radio's ability to communicate its messages unframed and deliver them straight into the listener's mental and physical space.

Pallasmaa poses his concern about 'the dominance of vision and the suppression of other senses in the way architecture was taught, conceived and critiqued, and the consequent disappearance of sensory qualities from architecture' (2012: 11). This workshop was informed by this notion, allowing young architects to consider and use all of their senses in their work. This particular drawing seems to be an apt representation of the complex tensions between the oral, the aural and the visual. Abstraction becomes a multifaceted concept here and it could be the task of a later to article to only consider these tensions as they emerge in radiophony.

4.
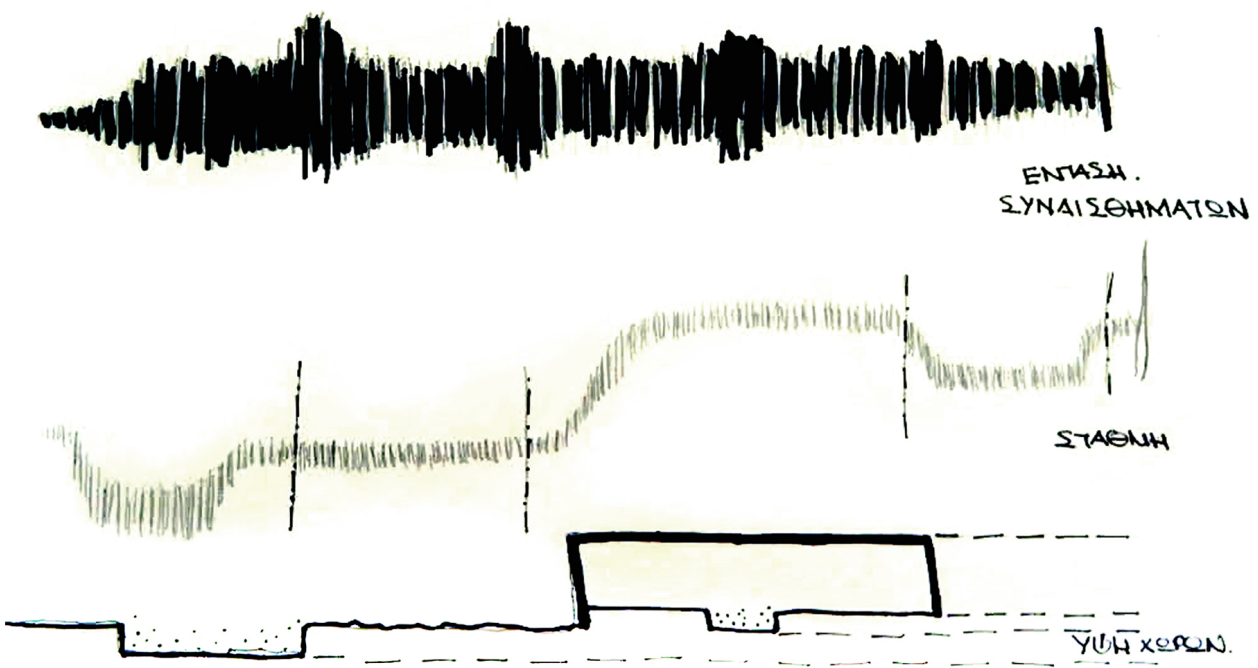

Figure 4. Drawing by Lydia Kyprioti 
'The Tension between Interior and Exterior' is another of Zumthor's elements that create atmosphere in architecture (2006: 45). While he describes this as the relationship between the outside and the inside of a building, what the student in Figure 4 seems to be doing is drawing the interior world of the protagonist in a direct relationship to the spaces that the character moves within: the three elements of these drawings are defined by the student as (starting from the top), 'intensity of emotions', 'level', 'elevation of spaces'. It is meaningful to consider here the direct juxtaposition between the perceived internal emotional state of the character and the spaces that this character inhabits.

Despite the absence of words, the atmosphere of the radio play seems to allow for an emotional response. We can indeed hear some bodily noises as the protagonist runs, walks, struggles, eats, but I argue that the emotional state captured in the student design is not only attributed to those elusive bodily sounds; rather they are largely generated by atmosphere, or in audio production terms, actuality. While in radio studies intimacy is often attributed to the oral, Sachs has achieved a different type of aural intimacy that is largely connected to space and the particular sonic landscapes that the protagonist inhabits. Pallasmaa discusses 'architectures of hearing' and asserts that 'every building or space has its characteristic sound of intimacy or monumentality, invitation or rejection, hospitality or hostility (2012: 53-54). Indeed, the spaces that the protagonist in The Revenge moves through are loaded with emotional significance, for example a prison, a home, a town street, a river. Pallasmaa continues: '[t]he echo of steps on a paved street has an emotional charge because the sound reverberating from surrounding walls put us in direct interaction with space' (2012: 55). The author talks about the first-hand experience of being in a place, which 
is the main principle of binaural audio production. In an audio story, the listener's imagination is allowed to ascribe subjective emotion to space, unbound from vision. In binaural recording and headphone listening this is heightened by enhancing in the listener the sense of inhabiting an imagined space.

In radio there also exists a tension between the interior and the exterior, not dissimilar to Zumthor's definition of this tension as an element of atmosphere in architecture. Radio happens through the intimate superimposition of three spaces: the physical space that the listener inhabits; the space that the radio producer creates through recording and editing; and the indefinable space within the listener's head deriving from and within her imagination. Atmosphere in radio, thus, apart from a technical term meaning 'actuality' might be defined as a type of intimacy that derives from the complex interactions between those three spaces.

\section{Imagination}

Andrew Crisell notes the significance of the listener's imagination in radio: 'the distinctiveness of radio is not that it involves the imagination while the other media do not, but that it involves it to a different extent' (1994: 9, original emphasis). Gregory Whitehead makes a similar point in his essay 'Speleology', where he states that, '[w]riting] radio performs a suggestion that can only be completed in the heads of individual auditors, a completion that takes place in the privacy of their own grotto' (1984: 3, original emphasis). ${ }^{3}$ As in radio, atmosphere in architecture seems to be the subjective result of a similar 'suggestion', which despite being immaterial and 
imagined, results from a well-defined structure. Juhani Pallasmaa argues for the importance of the senses in architecture, stating that,

Architecture does not make us inhabit worlds of mere fabrication and fantasy; it articulates the experience of our being-in-the-world and strengthens our sense of reality and self. The sense of self strengthened by art and architecture also permits us to engage fully in the mental dimensions of dream, imagination and desire. (2012: 12-13)

The idea of the dream is pertinent here. French philosopher Gaston Bachelard in a short essay titled Reverie and Radio written in 1951, offers a further connection between architecture and radio in the ways that they create emotive responses. ${ }^{4}$ Bachelard conceptualizes radio space as an archetype of the home, thus revealing the idea of radiophonic space as an intimate, private one:

the theme [of the home] is thoroughly rooted in the psychism of every individual. To develop it is to show that there is no more picturesque, that the picturesque is precisely fantasy, entertainment, that it must arouse some response in the mind of the individual. We can ask him to dream of a home, an interior. [...] It is a question of showing the listener little by little the essence of inward reverie. This is why the theme of the home - the seat of privacy and inwardness - lends itself so perfectly to the purpose. ${ }^{5}$ (Bachelard in Plantenga et al. 1993: 219-20, emphasis added) 
Radio contains spaces but it is also a space in itself. Radiophony, may be defined as what happens when a sonic construction enters a listener's ear. Equally, home is a feeling an inhabitant gets upon entering a built space. Atmosphere is common in radio and architecture because it is an abstract, immaterial emotive space which results from a well-designed construction. A radio producer, like an architect, supplies the listener - inhabitant with a construction, pregnant with emotive possibilities. An architect, like a radio producer, knows that the space she builds contains an indefinite number of stories within it. Pallasmaa writes that:

Architectural theorizing, education and practice have primarily been concerned with form. Yet, we have an astonishing capacity to perceive and grasp unconsciously and peripherally complex environmental entities and atmospheres. Atmospheric characteristics of spaces, places and settings are grasped before any conscious observation of details is made. Despite the obvious importance of atmospheric perception, it has hardly been introduced in architectural discourse. (2012: 15)

In the workshops reflected on in this article, the architecture students were encouraged to consider that if they borrow some of the ideas and practices of radio production and, indeed radio listening, they might be able to examine the idea of atmosphere under a different light. Radio creates intimacy through imagination. By using radio as an exercise in atmosphere, we attempted to inspire these young architects to build strong, well-constructed spaces like radio producers do; but not before first drawing them from imagination, just like radio listeners do. 


\section{Conclusion: Radio Studies}

Throughout this article, I have argued for the benefits of using a radio play as a pedagogical tool for understanding core concepts in the study of architecture. This may, upon first reading, appear to be the singular core of this work, and a radio scholar might wonder why such an article appears in a Radio Journal. However, my analysis of this collaborative pedagogical initiative also celebrates the interdisciplinarity of radio studies. I invite the reader to consider three major points as they relate to radio studies: First, the analysis of this radio play by using a combination of architectural and radio theory is a suggestion for how the radio scholar and educator may embellish their research methods and educational reach. Second, this work aims to add to a body of work that reveals radio studies as an interdisciplinary field. Third, with the current re-emergence of binaural audio, headphone listening and virtual-reality technologies, it is relevant to re-visit the ways in which radio can convey space. And being able to do the latter through the analysis of a radio play from 1978 is another indicator of radio's resilience and its pioneering powers.

In the October 2018 edition of the Radio Journal, Kate Lacey revisited the idea of radio studies as a field of research (2018: 109-26); an idea that indeed took some time to establish itself but is now firmly rooted and excitingly flourishing. Lacey in her article reiterates her position from ten years ago (2008: $21-32)$, that radio studies is and should be a place of interdisciplinarity and that an idea of a 'singular thing called radio' should not hinder the incredible advantage our field has due to its multiple intricacies. Rather pertinently for this article, Lacey supports her argument by 
bringing ideas of materiality and immateriality into play and posits that the same argument 'might go for the idea of 'radio studies' (2018: 110). She writes:

In other words, 'radio' is not just a historical or material artefact, but is, at root, an intellectual artefact. This matters - and not just because of the ways in which the mutable materiality of the world (the changing matter and matters of radio), is made to fit the abstract idea. By sleight of hand, or ideological move, the artifice of that abstraction then seems synthetically to equate to and exhaust its object. (2018: 110).

My study outlined in this article is located within this context. It is by relating to other things in the world through radio that this article attempts to further take advantage of the unique position that the radio theorist find herself in. As Lacey puts it:

focusing on an auditory medium in an age of spectacle, provides a very good platform from which to embark on such undisciplined interdisciplinary adventures, and that in venturing out with our antennae differently attuned, we might bring something fresh to those other fields. (2018: 111).

Radio and architecture cannot merely be defined by the lines that we have to draw in order to see them. Rather, we have to listen out for the things that they contain - the things that they bring into being. Radio and architecture alike are defined by the imaginative and emotive potential that an unopened box contains - only to take shape once someone has opened the box. 


\section{References}

Arnheim, Rudolf (1936), Radio, London: Faber \& Faber Ltd.

Burch, James (2015), 'What is atmosphere? Architectural students conversational, collaged \& diptychal definitions', Atmospheres: Morgan Centre Interdisciplinary Conference, Manchester University, Manchester, 1-2 July, http://eprints.uwe.ac.uk/28490. Accessed 4 July 2018.

Crisell, Andrew (1994), Understanding Radio, London: Routledge.

Crook, Tim (2012), The Sound Handbook, New York: Routledge.

Fischer, Sabine Von and Touloumi, Olga (2018), 'Sound modernities: Histories of media and modern architecture', The Journal of Architecture, 23:6, pp. 873-80.

Frascari, Marco (2011), Eleven Exercises in the Art of Architectural Drawing: Slow Food for the Architect's Imagination, New York: Routledge.

Hendy, David (2000), Radio in the Global Age, Cambridge: Polity Press.

I Did It My Way: Andrew Sachs (2017), BBC Radio 4 Extra, 4, United Kingdom, 4 February, 19.00, https://www.youtube.com/watch?v=tsAdYGdZc88\&t=77s , Accessed 25 November 2018. 
Karathanasopoulou, Evangelia (2014), 'An examination of the concept of intimacy in radio studies, combining mainstream and non-mainstream theories and practices', doctoral thesis, University of Sunderland, Sunderland, United Kingdom.

Lacey, Kate (2008), 'Ten years of radio studies: The very idea', Radio Journal International Studies in Broadcast \& Audio Media, 6:1, pp. 21-32.

(2013), Listening Publics: The Politics and Experience of Listening in the Media Age, Cambridge: Polity Press.

(2018), 'Up in the air? The matter of radio studies', Radio Journal-International Studies in Broadcast \& Audio Media, 16:2, pp. 109-26.

Pallasmaa, Juhani (2012), The Eyes of the Skin: Architecture and the Senses, Chichester: Wiley

Plantenga, Bart, Strauss, Neil and Mandl, Dave (eds) (1993), Radiotext(E), New York: Automedia.

Roginska, Agnieszka and Geluso, Paul (eds) (2017), Immersive Sound: The Art and Science of Binaural and Multi-Channel Audio, New York: Focal Press.

Sheridan, Ted and Lengen, Karen Van (2003), 'Hearing architecture', Journal of Architectural Education, 57:2, pp. 37-44. 
Shingler, Martin and Wieringa, Cindy (1998), On Air: Methods and Meanings of Radio, London: Arnold.

The Revenge (1978), BBC Radio 3, United Kingdom, 1 June, 21.45, https://www.youtube.com/watch?v=tsAdYGdZc88\&t=77s. Accessed 25 November 2018.

Whitehead, Gregory (1984), 'Speleology’, Ear, 8:5, 3.

Wigley, Mark (2015), Buckminster Fuller Inc: Architecture in the Age of Radio, Zurich: Lars Müller Publishers.

Wissmann, Torsten (2014), Geographies of Urban Sound, Surrey: Ashgate.

Yusaf, Shundana (2014), Broadcasting Buildings: Architecture On The Wireless. 1927-1945, Cambridge, MA: The MIT Press, eBook Collection (EBSCOhost), EBSCOhost, viewed 4 July 2018.

Zumthor, Peter (2006), Atmospheres: Architectural Environments, Surrounding Objects, Basel: Birkhäuser.

\section{Contributor details}

Dr Evi Karathanasopoulou studied classical music in Athens and then came to the United Kingdom to study media production and radio. She gained a first class (Hons) BA in media production: television and radio at the University of Sunderland and an 
MA in Radio at Goldsmiths College, University of London. She has worked as a radio producer and presenter in Greece and the United Kingdom. She gained her Ph.D. at the University of Sunderland, researching radio theory and issues around the radio voice and intimacy. She is now a senior lecturer in audio production at Bournemouth University, teaching on a range of production and theory units, including interactive documentary production. She supervises a range of student graduate production work, including audio and media-art installation projects. Her latest practice output is an audio installation artwork created as part of an international collaboration with the Goethe-Institut's Freiraum project.

Contact:

Weymouth House W212, Talbot Campus, Fern Barrow, Poole, BH12 5BB, UK.

E-mail: evik@bournemouth.ac.uk

Info : https://staffprofiles.bournemouth.ac.uk/display/evik

https://orcid.org/0000-0001-7055-6555

Notes

\footnotetext{
${ }^{1}$ Peter Zumhtor asserts that this feeling is created through a combination of nine material and immaterial elements in that space: The Body of Architecture /Material Compatibility/ The Sound of a Space/ The Temperature of a Space/ Surrounding Objects/ Between Composure and Seduction (Movement) / Tension Between and Interior and Exterior / The Levels of Intimacy (Scale, size, dimensions)/ The Light on Things (Zumthor 2006). Here I argue that many of these elements relate to radio and
} 
the ways it evokes emotion and, in particular, to how The Revenge radio play does the latter. Due to the limits and constraints of a journal article, here we will only be looking at some of these elements.

${ }^{2}$ My doctoral thesis, 'An examination of the concept of intimacy in radio studies, combining mainstream and non-mainstream theories and practices', provides a full analysis of the concept of intimacy and its significance in the study of radio (2014). ${ }^{3}$ The metaphor of a cave is an interesting one as it evokes an explicitly private space, one that is characterized by darkness. This is an apt metaphor for radio's blindness and its appeal to the imagination.

${ }^{4}$ The Oxford Dictionary defines the word reverie as 'a state of being pleasantly lost in one's thoughts; a daydream' deriving from 'Old French reverie "rejoicing, revelry", from rever "be delirious".

${ }^{5}$ Crisell also uses the word 'inward' in his discussion of intimacy, writing, '[...] while radio is a long-distance mode of communication it is also an inward, intimate medium [...]' (1994: 11, original emphasis). 